\section{Ecosystem trends}

SIR - The relationship between primary production by plants and the biomass of herbivores has implications for the current debate on principles of population regulation. A simple, positive linear correlation is predicted by theories where herbivores are assumed to be limited by their food resources ${ }^{1,2}$ and by the theory of ratio-dependent predation ${ }^{3}$. Conversely, models assuming preydependent predation ${ }^{4-6}$ predict that the biomass of herbivores no longer increases in ecosystems productive enough to support efficient carnivores.

McNaughton et al ${ }^{7,8}$ concluded that herbivore biomass $(B)$ increases with

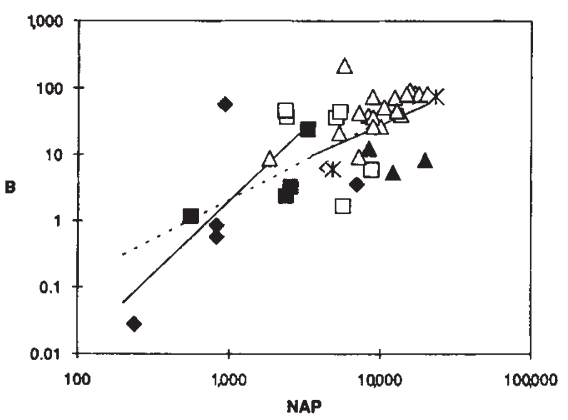

Relationship between net above-ground primary productivity (NAP) and herbivore biomass $(B)$ using our version of the data set. Dotted line, linear regression for the entire data set $(y=1.19 \times-3.25$, $\left.P<0.001, r^{2}=0.52\right)$; solid lines, regressions above and below the breakpoint (see text). Filled squares, desert; filled diamonds, tundra; open triangles, tropical grassland; open squares, temperate grassland; open diamonds, old field; filled triangles, temperate forest; star, tropical forest.

increasing net above-ground primary productivity $(N A P)$ according to the model $B=10^{-4.79}$. NAP $P^{1.52}$. We reanalysed their data set using a logarithmic regression model in which herbivore biomass levels off $(y=a \log (x)$, where $y=\log B$ and $x=\log N A P)$. The performance of our model $\left(r^{2}=0.577\right)$ is practically identical to the performance of their log-linear model $\left(r^{2}=0.575\right)$.

We also repeated their work using the references they cited or mentioned to us in correspondence. We tried to apply the same criteria of selection, except that we also required that the systems are free from obvious, significant human impacts on trophic dynamics. When minimum and maximum herbivore biomasses were reported, we computed long-term averages if possible. If not, the reference was excluded. We accepted the Canadian high $\operatorname{arctic}^{9}$ data which were rejected by McNaughton et al., and we rejected several temperate data points included in their analysis. Our data set (see figure) became so different from theirs that it was impossible even to identify the points representing the same system. Nevertheless, our general conclusions were similar. The logarithmic model with a built-in levelling off performed marginally better $\left(r^{2}=0.551\right)$ than the linear one $\left(r^{2}=0.524\right)$.

Another way to look at the situation is to test whether the slope of the regression line is significantly lower in productive systems than in barren ones. We have done this for both versions of the data set. We chose a breakpoint based on the model reported in ref. 5 and on the assumption of a shoot:root allocation ratio of 1:3 typical for tundra and grassland systems ${ }^{10-13}$, which gives a breakpoint between barren and productive systems at $N A P=175 \mathrm{~g}^{-2} \mathrm{yr}^{-1}$ or 3,500 $\mathrm{kJm}^{-2} \mathrm{yr}^{-1}$.

In the data set of McNaughton et al., the regression line for barren systems was $y=1.44 \times-4.60 \quad\left(r^{2}=0.16, P=0.16\right.$, $n=14$ ) while the one for productive systems was $y=1.05 \times-2.91 \quad\left(r^{2}=0.24\right.$, $P=0.002, n=36)$. In our data set, barren systems obtained the regression $y=2.20 \times-6.30 \quad\left(r^{2}=0.64, \quad P=0.002\right.$, $n=12$ ), whereas the regression for productive systems was $y=1.01 \times-2.60$ ( $\left.r^{2}=0.16, P=0.03, n=30\right)$. The two data sets thus have opposite implications about the statistical strength of the regression below and above the threshold. However, slopes are consistently lower for productive systems than for barren ones with a statistically significant difference in both cases (for the data of McNaughton et al., $t=7.41, P<0.001$, d.f. $=46 ;$ for our data, $t=22.95$, $P<0.001$, d.f. $=38$ )

The relation of these results to various theories is complicated. The difference in the slopes is inconsistent with theories of strict resource-limitation ${ }^{1,2}$ and with the theory of ratio-dependent predation ${ }^{3}$. The existence of a significantly positive slope even in productive areas is inconsistent with laissez-faire preydependent models ${ }^{4,5}$ but consistent with

\section{White, T. R. C. Oecologia 33, 71-86 (1978) \\ 2. Caughley, G. Ecology 51, 52-72 (1970).}

3. Arditi, R. \& Ginzburg, L. R. J. theor. Biol. 139, 311-326 (1989)

4. Rosenzweig, M. L. Science 171, 385-387 (1971)

5. Oksanen, L., Fretwell, S.D., Arruda, J. \& Niemelä, P. Am. Nat. 118, 240-261 (1981)

6. Oksanen, L. Evolutionary Ecology (in the press)

7. McNaughton, S. J., Oesterheld, M., Frank, D. A. \& Williams, K. J. Nature 341, 142-144 (1989).

8. McNaughton, S. J., Oesterheld, M., Frank, D. A. \& Williams, K. J. in Comparative Analyzes of Ecosystems (eds Cole, J.et al.) 120-139 (Springer, in the press).

9. Bliss, L. C. in Truelove Lowland, Devon Island, Canada a High Arctic Ecosystem (ed. Bliss, L. C.) 657-675 (Univ. of Alberta Press, Edmonton, 1977).

10. Sims, P. L. \& Coupland, R. T. in Grassland Ecosystems of the World (ed. Coupland, R. T.) 49-72 (Cambridge Univ. Press, 1979).

11. Wielgolaski, F. E. Ecological Studies 16, 121-128 (1975).

12. Muc, M. in Truelove Lowland, Devon Island, Canada: a High Arctic Ecosystem (ed. Bliss, L. C.) 157-184 (Univ. of Alberta Press, Edmonton, 1977)

13. Miller, P. C., Webber, P. J., Oechel, W. C. \& Tieszen, L. $L$. in An Arctic Ecosystem: the Coastal Tundra at Barrow (eds Brown, J., Miller, P. C., Tieszen, L. L. \& Bunnell, F. L.) 66-101 (Dowden, Hutchinson \& Ross, Stroudsburg. 1980) prey-dependent models with interference, spatial heterogeneity and/or evolutionary and behavioural responses to predation $^{6}$.

Nevertheless, we warn against overinterpreting the results. The data are noisy and represent systems with various degrees of human disturbance. It is difficult to distinguish patterns from scatter and risky to assume that all patterns reflect natural dynamics.

JON MOEN LAURI OKSANEN

Department of Ecological Botany, University of Umeå

S-901 87 Umeå, Sweden

\section{No X-ray lens}

SIR - Suehiro et al. ${ }^{1}$ propose the use of refractive lenses for focusing $X$ rays. Similar lenses have previously been considered $^{2}$, which have not been made or used for several reasons, including the following.

(1) Because the X-ray refractive indices of all materials are very close to unity, such lenses have very long focal lengths and small numerical apertures, resulting in poor spatial resolution capabilities. The examples given by Suehiro et al. have numerical apertures of a few times $10^{-5}$, resulting in limiting resolutions of a few micrometres for $8-\mathrm{keV}$ $\mathrm{X}$ rays. This is not a problem in the proposed use of such lenses in long synchrotron beam lines, but would be in other applications.

(2) The X-ray optical constants of materials are not well known, particularly the refractive indices. Therefore it is difficult to design and make a lens to a required specification. This is not so serious a problem for zone plates and mirrors for which the focal lengths do not depend on the refractive index.

(3) The design of refractive lenses for soft $X$ rays, for use in, for example, $\mathrm{X}$-ray microscopy, is limited by the requirement that the maximum thickness of the lens has to be less than about 1 $\mu \mathrm{m}$ to prevent excessive absorption losses in the lens material ${ }^{2}$. This results in limits on the size and focal length of such a lens, restricting the achievable spatial resolution to a few micrometres. Zoneplate X-ray microscopes now routinely achieve resolutions of $50 \mathrm{~nm}$ (ref. 3), and thus it makes little sense to consider the use of refractive lenses for X-ray microscopy.

Department of Physics,

A. G. MICHETTE

King's College London

The Strand, London WC2R 2LS, UK

1. Suehiro, S., Miyaji, H. \& Hayashi, H. Nature 352 385-386 (1991)

Michette, A.G. Optical Systems for Soft $x$ Rays (Plenum New York, 1986).

3. Michette, A.G., Morrison, G.R. \& Buckley, C.J. (eds) $X$-Ray Microscopy III (Springer. Berlin, in the press). 